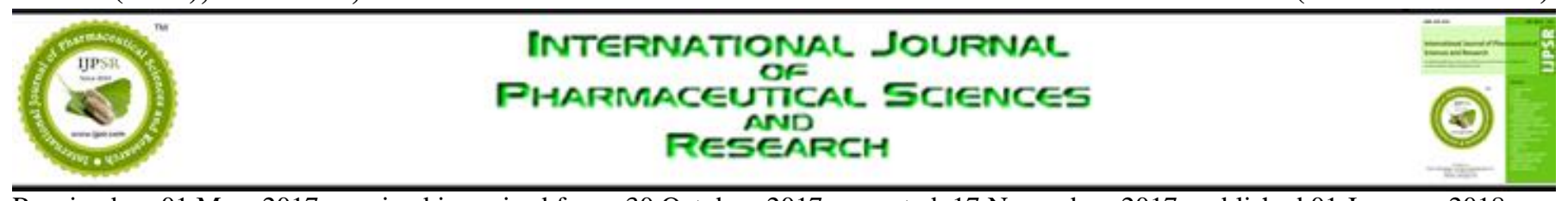

Received on 01 May, 2017; received in revised form, 30 October, 2017; accepted, 17 November, 2017; published 01 January, 2018

\title{
FORMULATION DEVELOPMENT AND EVALUATION OF CLOPIDOGREL BISULFATE TRANSDERMAL PATCHES
}

Padmaja Bookya ${ }^{* 1}$, Ramakrishna Raparla ${ }^{1}$, Harikishan Sriramula ${ }^{1}$ and Sunitha Tarigopula ${ }^{2}$

Department of Pharmaceutics ${ }^{1}$, Department of Pharmaceutical chemistry ${ }^{2}$, Vaageswari Institute of Pharmaceutical Science, Karimnagar - 505481, Telangana, India.

Keywords:

TDDS, Clopidogrel bisulphate, HPMC, DMSO, PVP, EC, PEG - 400

Correspondence to Author:

Bookya Padmaja

Asstistant Professor,

Department of Pharmaceutics,

Vaageswari Institute of Pharma-

ceutical Sciences, Karimnagar -

505481, Telangana, India.

E-mail: bookyapadmaja@gmail.com
ABSTRACT: Clopidogrel bisulphate is a drug used in inhibiting the platelet aggregation and also used in the treatment of cardiovascular disorders. It acts by inhibiting the adenosine diphosphate and is almost absorbed (98\%) after oral administration. Approximately $50 \%$ of drug is excreted in urine and $40 \%$ in feces. The plasma half life of drug is about 8 hours which makes frequent dosing necessary to maintain the therapeutic blood levels of drug for a long term treatment. So the transdermal patches were used to deliver the drug directly to systemic circulation through skin. The transdermal patches were prepared by solvent evaporation method. The influence of varying the combination of polymer concentrations at different ratio was evaluated. The polymers used in this study did not alter physicochemical properties of the drug. All the batches were evaluated for physical appearance, thickness, weight variation and drug content uniformity. The in-vitro drug dissolution study was carried out using Franz diffusion apparatus and the release mechanisms were explored. Mean dissolution time is used to characterize drug release rate from transdermal patch and indicates the drug release retarding efficiency of polymer. The time taken for $92 \%$ of drug release was found to be within 16 hours with F4 formulation while all other formulations were showing $85 \%$ drug release for $10 \mathrm{hrs}$ and hence the concentration of PVP and ethyl cellulose 200 $\mathrm{mg}$ was best. Hence the optimized formulation was found F4. All the prepared patches exhibited zero order release kinetics, governed by a diffusion mechanism.
INTRODUCTION: Transdermal Drug Delivery System (TDDS) are adhesives drug contains devices of defined surface area that delivers predetermined amount of drug to the intact skin at a preprogrammed rate, the TDDS has gained importance in recent years ${ }^{1}$. Skin is the largest organ of the body and it protects the body from the environmental factors. In order to achieve therapeutic values of a drug product delivered through skin, it is required to overcome the skin barriers $^{2}$.

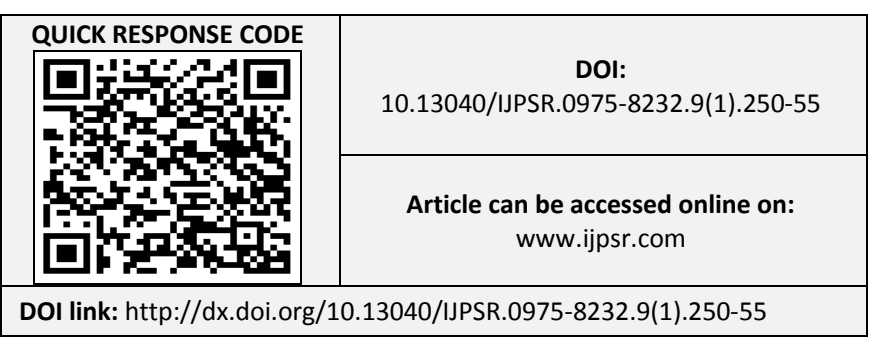

Transdermal drug delivery system are defined as self-contained discrete dosage forms which are also known as "patches" when patches are applied to the intact skin, deliver the drug through the skin at a controlled rate to the systemic circulation ${ }^{3}$. TDDS offers many advantages over conventional injection and oral methods. It reduces the load that the oral route commonly places on the digestive tract and liver.

It enhances patient compliance and minimizes harmful side effects of a drug caused from temporary overdose. Another advantage is convenience, especially notable in patches that require only once weekly application. Such a simple dosing regimen can aid in patient adherence to drug therapy ${ }^{4}$. Some chronic diseases like diabetes, hypertension, tuberculosis, cancer require prolong administration of drugs and frequent 
dosing to maintain constant drug plasma concentration level and may lead to poor patient compliance. Many orally administered drugs can irritate the GI tract or undergo first pass metabolism and leads to poor bioavailability ${ }^{5}$.

Clopidogrel bisulfate is an anti-platelet drug undergoes hepatic first pass metabolism and low oral bioavailability $(50 \%)$. Hence it is suitable for formulation as a transdermal patch. Drug molecules in contact with the skin surface can penetrate by three potential pathways: through the sweat ducts, via the hair follicles and sebaceous glands or directly across the stratum corneum. The plasma half-life is about 8 hours which makes frequent dosing necessary to maintain the therapeutic blood levels of the drug for a long term treatment. Hence it is suitable for formulation as a transdermal patch ${ }^{6}$.

Therefore, clopidogrel bisulphate is an ideal drug for the transdermal drug delivery. Development of clopidogrel bisulphate patches using PVP, ethyl cellulose, HPMC, PEG-400 as plasticizer and DMSO as a permeation enhancer by using solvents at equal ratios. Evaluation of prepared patches by in-vitro drug release studies by Franz diffusion apparatus and to study the release kinetics of drugs from all the formulations.

\section{MATERIALS AND METHODS:}

Materials: Clopidogrel bisulfate was a gift sample from Aurobindo Pharma Ltd, Hyderabad. Poly vinyl pyrrolidone, hydroxy propyl methyl cellulose, ethyl cellulose were received from Loba Chemicals, Mumbai. Dimethyl sulfoxide, polyethylene glycol, chloroform were procured from S. D. Fine Chemicals, Mumbai.

Preparation of Clopidogrel bisulphate Transdermal patches: Clopidogrel bisulphate transdermal patches were prepared by solvent evaporation method. Weighed quantities of polymers like hydroxy propyl methyl cellulose, Poly vinyl pyrrolidone, and ethyl cellulose were dissolved in chloroform and ethanol solvent mixture. The drug was added to the above polymer solution along with polyethylene glycol as plasticizer and dimethyl sulfoxide as permeation enhancer and thoroughly mixed to form a homogeneous mixture. The volume was made up to $10 \mathrm{ml}$ with chloroform. Then the drug solution was added to the polymeric solution, casted on to petriplates of surface area about 69.42 sq.cm, allowed for air drying overnight followed by vacuum drying for 8$10 \mathrm{hr}$. The entire sheet was cut into small patches with an area of $5 \mathrm{~cm}^{2}$ i.e. with a diameter of $2.5 \mathrm{~cm}$. About 10 patches were obtained from each sheet ${ }^{7}$.

\section{Evaluation of Prepared Trans-dermal Patches:}

Physical Appearance: All the prepared transdermal patches were visually inspected for color, clarity, flexibility and smoothness ${ }^{8}$.

Thickness of the Patch: Thickness of each transdermal patch was determined via utilizing a micrometer screw gauge placed at six distinct positions. The average thickness and standard deviation values of six readings were calculated for each batch of drug loaded patch ${ }^{9}$.

Weight Uniformity: It was studied by individually weighing 10 randomly selected transdermal patches and average weight was calculated on digital balance (Shimadzu, AUX220, Japan). The individual weights should not deviate significantly from the average weight ${ }^{10}$.

Drug Content: An accurately weighed portion of film (about $100 \mathrm{mg}$ ) is dissolved in $100 \mathrm{ml}$ of suitable solvent in which drug is soluble and then the solution is shaken continuously for $24 \mathrm{~h}$ in shaker incubator (Rajendra Electrical Industries Ltd, Hyderabad). Then the whole solution is sonicated, filtered, drug in solution is estimated by appropriate dilution and analysed by (Shimadzu, Japan) UV -Spectrophotometrically ${ }^{11}$.

Percentage of Moisture Uptake: The weighed films were kept in a desiccators (Borosil Hyderabad, India) at room temperature for 24 hours and then exposed to $84 \%$ relative humidity using a saturated solution of potassium chloride. Finally the films were weighed and the percentage of moisture uptake is calculated as the difference between the final and initial weight with respect to initial weight 12 .

Percentage moisture uptake $=[$ Final weight - Initial weight/Initial weight] $* 100$

Folding endurance: The folding endurance of patches was determined by repeatedly folding a strip of film at the same place till it tends to break. It is determined as the number of times the film is 
folded at the same place either to break the film or to develop visible cracks ${ }^{13}$.

In-vitro Release Studies: In-vitro drug release of trans-dermal patches can be studied using Franz diffusion cell (most commonly used) with an effective permeation area of $1.0 \mathrm{~cm}^{2}$ and receptor cell volume of $10 \mathrm{ml}$. The temperature is maintained at $32^{\circ} \mathrm{C} \pm 0^{\circ} \mathrm{C}$. The synthetic cellophane membrane was mounted between upper donor and patch placed on upper receptor compartment of the diffusion cell. The lower receptor compartment is filled with $10 \mathrm{ml}$ phosphate buffer $\mathrm{pH} 7.4$ which is constantly stirred on a magnetic stirrer (Remi Hyderabad, India) at $100 \mathrm{rpm} .2 \mathrm{ml}$ samples were withdrawn from receptor compartment through the sampling port at predetermined time interval and are analysed for drug release at $247 \mathrm{~nm}$ spectrophotometrically ${ }^{14}$ (Shimadzu, AUX220, Japan).

Drug Release Kinetics Mechanism: To interpret the mechanism and kinetics of drug release, the result outcome of in-vitro drug release study were applied with different kinetic equations like zero order ( $\%$ drug release $v s$. time), first order (log $\%$ unreleased drug vs. time) and Higuchi matrix (\% drug release $v s$. square root of time). Drug release data was further analysed by Peppas equation, $\mathrm{Mt} / \mathrm{M} \infty=\mathrm{ktn}$, where $\mathrm{Mt}$ is the amount of drug released at time $t$ and $M \infty$ is the amount released at time $\infty$, the $\mathrm{Mt} / \mathrm{M} \infty$ is the fraction of drug released at time $\mathrm{t}, \mathrm{k}$ is the kinetic constant and $\mathrm{n}$ is the diffusion exponent, a measure of the primary mechanism of drug release to define a model which will represent a better fit for the formulation. Regression co-efficient $\left(\mathrm{r}^{2}\right)$ values were calculated for the linear curves obtained by regression analysis of the above plots ${ }^{15}$.

RESULTS: In the present work, transdermal patches were prepared by using solvent evaporation method as it was feasible and simple. The best parameters obtained for clopidogrel bisulphate patches were evaluated based on drug release.

\begin{tabular}{ccccccccccc} 
TABLE 1: FORMULA OF CLOPIDOGREL BISULPHATE TRANSDERMAL PATCHES \\
\hline Ingredients & CBF1 & CBF2 & CBF3 & CBF4 & CBF5 & CBF6 & CBF7 & CBF8 & CBF9 \\
\hline Clopidogrel bisulphate (mg) & 50 & 50 & 50 & 50 & 50 & 50 & 50 & 50 & 50 \\
PVP(mg) & 250 & 250 & 250 & 250 & 250 & 250 & - & - & - \\
HPMC(mg) & 250 & 750 & 1250 & - & - & - & 250 & 750 & 1250 \\
EC(mg) & - & - & - & 250 & 750 & 1250 & 250 & 750 & 1250 \\
DMSO(ml) & 15 & 15 & 15 & 15 & 15 & 15 & 15 & 15 & 15 \\
PEG -400(ml) & 15 & 15 & 15 & 15 & 15 & 15 & 15 & 15 & 15 \\
Chloroform: ethanol(ml) & 10 & 10 & 10 & 10 & 10 & 10 & 10 & 10 & 10 \\
\hline
\end{tabular}

Evaluation Data of Clopidogrel bisulphate Transdermal Patches: The following studies were carried to find the effect of different ratios of polymers in combination.

TABLE 2: EVALUATION DATA OF CLOPIDOGREL BISULPHATE TRANSDERMAL PATCHES

\begin{tabular}{cccccc}
\hline $\begin{array}{c}\text { Batch } \\
\text { Code }\end{array}$ & $\begin{array}{c}\text { Thickness } \\
(\mathbf{m m})\end{array}$ & $\begin{array}{c}\text { Weight variation } \\
(\mathbf{m g})\end{array}$ & $\begin{array}{c}\text { Folding } \\
\text { endurance }\end{array}$ & $\begin{array}{c}\text { Drug content } \\
(\boldsymbol{\%})\end{array}$ & $\begin{array}{c}\text { \%oisture } \\
\text { uptake }\end{array}$ \\
\hline F1 & $206 \pm 6.18$ & $135 \pm 3.51$ & $22 \pm 2.20$ & $96.99 \pm 0.65$ & $0.78 \pm 1.02$ \\
F2 & $220 \pm 7.12$ & $166 \pm 4.52$ & $21 \pm 2.8$ & $97.2 \pm 0.65$ & $0.93 \pm 1.05$ \\
F3 & $232 \pm 7.18$ & $155 \pm 4.10$ & $28 \pm 2.40$ & $94.99 \pm 0.65$ & $0.80 \pm 1.10$ \\
F4 & $204 \pm 5.18$ & $160 \pm 4.20$ & $26 \pm 2.96$ & $96.56 \pm 0.65$ & $0.40 \pm 1.08$ \\
F5 & $204 \pm 5.18$ & $170 \pm 4.62$ & $27 \pm 2.38$ & $95.45 \pm 0.65$ & $0.70 \pm 1.07$ \\
F6 & $265 \pm 5.13$ & $140 \pm 3.70$ & $25 \pm 2.32$ & $96.72 \pm 0.65$ & $0.35 \pm 0.78$ \\
F7 & $280 \pm 1.60$ & $136 \pm 3.55$ & $31 \pm 3.1$ & $95.55 \pm 0.65$ & $0.25 \pm 0.45$ \\
F8 & $245 \pm 6.10$ & $176 \pm 1.72$ & $29 \pm 2.45$ & $98.22 \pm 0.65$ & $0.40 \pm 0.60$ \\
F9 & $278 \pm 4.60$ & $165 \pm 4.20$ & $30 \pm 2.63$ & $97.99 \pm 0.65$ & $0.93 \pm 0.75$ \\
\hline
\end{tabular}

S.D* is being calculated by taking 3 patches

TABLE 3: CUMULATIVE \% DRUG RELEASE DATA OF TRANSDERMAL PATCHES IN PHOSPHATE BUFFER pH 7.4 (CBF1- CBF5)

\begin{tabular}{cccccc}
\hline Time $($ Hr) & F1 & F2 & F3 & F4 & F5 \\
\hline 0 & 0 & 0 & 0 & 0 & 0 \\
1 & 12 & 18 & 16 & 13 & 14 \\
\hline
\end{tabular}




\begin{tabular}{cccccc}
\hline 2 & 21 & 23 & 25 & 19 & 22 \\
3 & 27 & 31 & 36 & 25 & 29 \\
4 & 35 & 38 & 39 & 33 & 35 \\
5 & 43 & 44 & 42 & 39 & 39 \\
6 & 57 & 48 & 51 & 45 & 42 \\
7 & 65 & 53 & 59 & 58 & 52 \\
8 & 71 & 58 & 63 & 62 & 59 \\
10 & 78 & 62 & 72 & 71 & 65 \\
12 & 83 & 68 & 78 & 75 & 78 \\
14 & 85 & 75 & 83 & 81 & 82 \\
16 & 91 & 88 & 89 & 92 & \\
\hline
\end{tabular}

TABLE 4: CUMULATIVE \% DRUG RELEASE DATA OF TRANSDERMAL PATCHES IN PHOSPHATE BUFFER pH 7.4 (CBF6- CBF9)

\begin{tabular}{ccccc}
\hline Time (Hr) & F6 & F7 & F8 & F9 \\
\hline 0 & 0 & 0 & 0 & 0 \\
1 & 21 & 24 & 17 & 16 \\
2 & 29 & 29 & 24 & 26 \\
3 & 35 & 34 & 31 & 34 \\
4 & 39 & 42 & 39 & 42 \\
5 & 42 & 49 & 42 & 48 \\
6 & 49 & 51 & 49 & 53 \\
7 & 54 & 59 & 53 & 59 \\
8 & 62 & 63 & 59 & 63 \\
10 & 69 & 71 & 66 & 69 \\
12 & 74 & 76 & 72 & 73 \\
14 & 79 & 82 & 79 & 79 \\
\hline
\end{tabular}

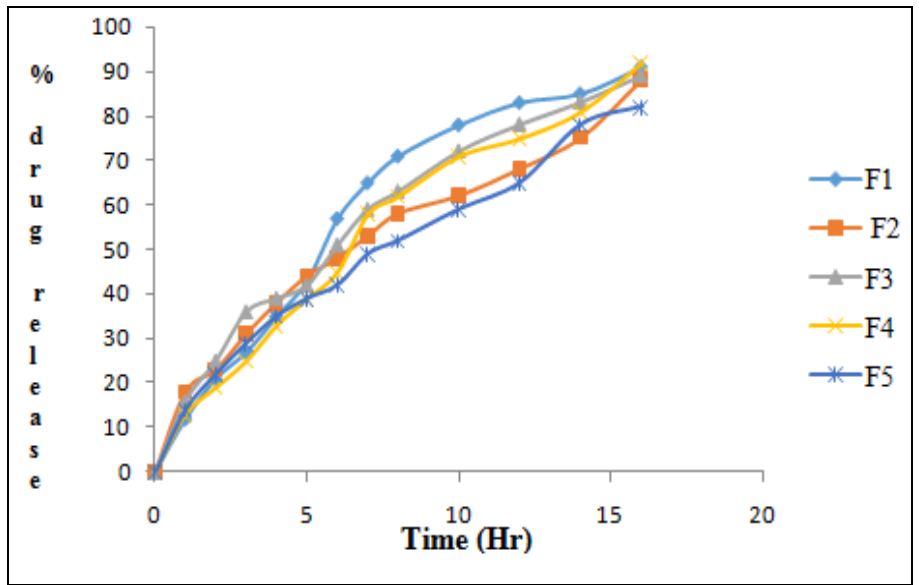

FIG. 1: \% DRUG RELEASE OF CLOPIDOGREL BISULPHATE FROM TRANSDERMAL PATCHES F1-F5

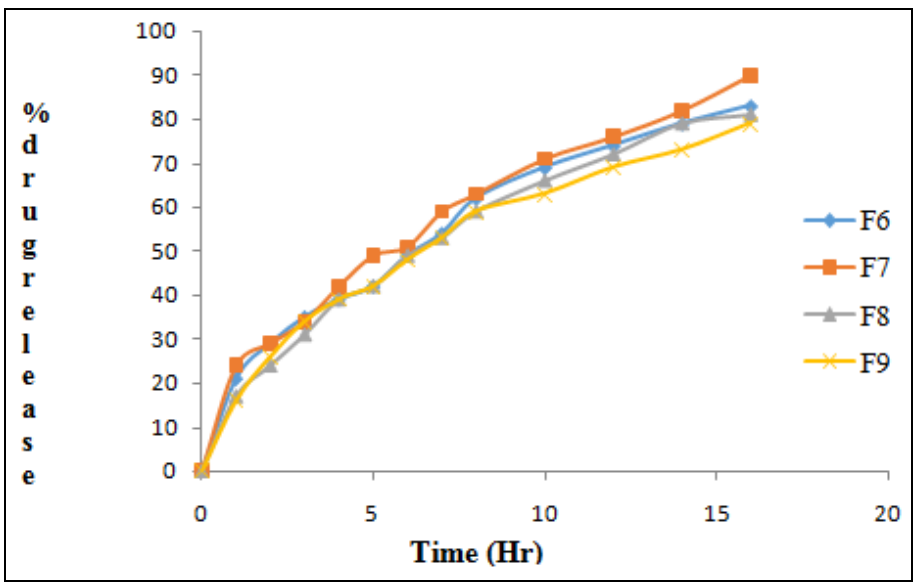

FIG. 2: \% DRUG RELEASE OF CLOPIDOGREL BISULPHATE FROM TRANSDERMAL PATCHES F6- F9

International Journal of Pharmaceutical Sciences and Research 
DISCUSSION: Physical Appearance of the polymers (Ethyl cellulose, Hydroxypropyl methyl cellulose, Poly vinyl pyrrolidone) used for the fabrication of transdermal systems showed good film forming properties. These prepared systems were thin, flexible, smooth and translucent and the method adopted for the systems was found satisfactory. Thickness of the transdermal patches in all 9 formulations was in the range of $206-278$ $\mathrm{mm}$ with low standard deviations.

The $\%$ of content uniformity in patches was determined by UV spectrophotometer ((UV 2060 Plus Analytical Technology, India). All the formulations are subjected for content uniformity and were in the range of $96.99-97.99 \%$. It was observed that all the formulations were as per I. P. specification limits the low values in standard deviation indicate uniform drug content in all the formulations. The average weight of the patches was in the range of $135-165 \mathrm{mg}$. The weights of all transdermal patches were found to be uniform with their low standard deviation. The folding endurance average values was found to be $22-30$. The \% moisture uptake was found to be 0.25 $0.93 \%$. Optimization of the formulated patches was done by performing in-vitro drug release studies using Franz diffusion cell with cellophane membrane. The \% drug release data and plot which were obtained for the transdermal patches in phosphate buffer $\mathrm{pH} 7.4$ was shown in Table 3, 4 and Fig. 1, 2 respectively were analyzed at $247 \mathrm{~nm}$ by UV - Spectrophotometer.

In most of the formulations with low concentration range of polymers the $\%$ drug release was attained up to $92 \%$. As we assume that with increase in concentration of polymer it may attain higher drug release. But according to drug release studies conducted by Franz diffusion apparatus the low concentration gave better drug release compared to increasing concentrations of polymers. But finally I would like to conclude that for preparation of transdermal patches low concentration of polymers will be suitable. Hence the patch with F4 formulation (PVP and EC) drug release was $92 \%$ hence it was the optimized batch. The cumulative amount of drug permeated per square centimetre of patches through membrane was plotted against time was fitted to zero, first, higuchi and peppas kinetic model. As indicated based on release profile it followed zero-order kinetics in all formulations. However, the release profile of the optimized formulation $\mathrm{F} 4\left(\mathrm{r}^{2}=0.982\right.$ for zero order) indicated that the drug from the patches was governed by a diffusion mechanism.

CONCLUSION: Delivery of drug into systemic circulation through skin has created lot of interest among pharmaceutical scientist during recent years. In order to provide a constant serum level of clopidogrel bisulphate over prolonged period of time polymers like HPMC, EC, PVP were selected in combinations like PVP: HPMC, PVP: EC and HPMC: $E C$ in different ratios $(1: 1,1: 3,1: 5)$. Transdermal patches were prepared by solvent evaporation technique. The patches exhibited good physical properties. The in-vitro studies were attempted using Franz diffusion cell. The transdermal patches were evaluated for physicchemical properties like thickness, weight variation, in-vitro drug release.

On evaluation of various parameters it was found that the polymers produced satisfactory results. Transdermal patches with PVP and HPMC combinations showed $91 \%$ drug release while PVP and EC showed $92 \%$ drug release. Finally combinations like HPMC and EC showed $90 \%$ drug release. The release rate increased with decrease in polymeric concentration. So the combinations of polymers like PVP and EC with low concentration were mostly suitable to prepare transdermal patches. The release kinetics of the formulation followed zero order release kinetics with higuchi release mechanism.

ACKNOWLEDGEMENT: The authors express their sincere thanks to management Dr. G. Srinivas Reddy, Karimnagar, India, for providing required facilities to carry out this research work.

CONFLICTS OF INTEREST: All authors have none to declare.

\section{REFERENCES:}

1. Karpagavalli L, Mahaeswaran A, Praveena P, Sharmila S, Priya $M$ and Meena B: Formulation and evaluation of transdermal patches of curcumin. Int. J Novel Trends Pharm Sci. 2017; 7(1): 22-26.

2. Bandyopadhyay A: Transdermal drug delivery systemquality by design approach. $\mathbf{J}$ of Bioanalysis and Biomedicine. 2017; 9(4): 217-219. 
3. Himanshi $\mathrm{T}$ and Ruchika S: Transdermal drug delivery system: a review. Int. J Pharm Sci. Res. 2016; 7(6): 22742290.

4. Verma G: Transdermal drug delivery system advance development and evaluation-a review. Int. J Pharm Sci. Res. 2017; 8(2): 385-400.

5. Rajesh A, Avinash $G$ and Bhagwan Swaroop M: Formulation and evaluation of transdermal patches of Torasemide. Int. J Advances Sci. Res. 2015; 1(1): 38-44.

6. Keerthi Priya J, Prem Kumar P and Shameera Begum SK: Formulation and evaluation of clopidogrel bisulphate transdermal patches using vegetable oils as permeation enhancer. Int. J Pharm Sci. Res. 2014; 5(2): 473-482.

7. Basha SAA and Maimoona M: Formulation and in-vitro evaluation of transdermal drug delivery system of captopril by employing natural polymers. Int. J Inno Pharm Sci. Res. 2017; 5 (08): 30-45.

8. Kalyani G, Bandhu D, Dinanath B and Sharma DK: Targetted drug delivery system of valsartan. Int. J Pharm Sci. Res.2015; 6(12): 5085-5101.

9. Patil VK and Shah H: Formulation and evaluation of transdermal patches of Indapamide. Int. J Pharm Res. BioSci. 2016; 5(2): 215-229.
10. Chakshu B, Monika S and Meenakshi B: Formulation and evaluation of transdermal patch of pregabalin. Int. J Pharm Sci. Res. 2012; 3(2): 569-575.

11. Kanabar VB, Patel VP and Doshi M: Formulation and evaluation of transdermal patch of cefdinir with various polymers. The Pharm Inn J. 2015; 4(6): 74-77.

12. Eisha $G$ and Kuldeep G: Formulation and evaluation of transdermal patch of acetohexamide. Eur J Pharm Medical Res. 2016; 3(7): 233-235.

13. Suneetha C, Uma Rajeswari B, Kiranmai M, Vidhyullatha $\mathrm{C}$ and Koteswara Rao G: Formulation and evaluation of transdermal drug delivery of topiramate. Int. J Pharm Invest. 2017; 7 (1):10-17.

14. Fathima SA, Begum S and Fatima SS: Transdermal drug delivery system. Int. J Pharm Clin Res. 2017; 9(1): 35-43.

15. Rakesh K, Nidhi $S$ and Kamal S: Formulation, optimization and evaluation of transdermal patches of salbutamol Sulphate. Int. J Pharm Sci. Res. 2016; 7(4): $1572-1579$.

How to cite this article:

Bookya P, Raparla R, Sriramula H and Tarigopula S: Formulation development and evaluation of clopidogrel bisulfate transdermal patches. Int J Pharm Sci \& Res 2018; 9(1): 250-55. doi: 10.13040/IJPSR.0975-8232.9(1).250-55.

All @ 2013 are reserved by International Journal of Pharmaceutical Sciences and Research. This Journal licensed under a Creative Commons Attribution-NonCommercial-ShareAlike 3.0 Unported License.

This article can be downloaded to ANDROID OS based mobile. Scan QR Code using Code/Bar Scanner from your mobile. (Scanners are available on Google Playstore) 